\title{
STUDI KARAKTER MORFOMETRIK DAN MERISTIK IKAN NOMEI (Harpadon nehereus) DI KALIMANTAN UTARA
}

\section{STUDY OF MORFOMETRIC AND MERISTIC CHARACTER OF NOMEI FISH (Harpadon nehereus) AT NORTH BORNEO}

\author{
Rafi Setiawan ${ }^{1}$, Ratna Suharti ${ }^{1 \#}$, Hendra Irawan ${ }^{2}$, Basuki Rachmad ${ }^{1}$, dan Dadan Zulkifli ${ }^{1}$ \\ ${ }^{1}$ Sekolah Tinggi Perikanan \\ Jl. Aup No. 1 Pasar Minggu, Jakarta Selatan \\ ${ }^{2}$ Kampus BAPPL-STP \\ Jl. STP Raya Karagantu, Serang, Banten \\ E-mail: ratnastp.rs75@gmail.com
}

(Diterima: 12 November 2019; Diterima setelah perbaikan: 11 Mei 2020; Disetujui: 12 Mei 2020)

\begin{abstract}
ABSTRAK
Penelitian ini bertujuan untuk mendreskripsikan karakteristik morfometrik dan meristik ikan nomei (Harpadon nehereus) di perairan Kalimantan Utara, dilakukan pada bulan Agustus hingga Oktober 2018. Metode pengambilan data yang digunakan adalah random sampling. Penentuan stasiun dilakukan berdasarkan lokasi penangkapan ikan nomei diperairan sebatik dan tarakan. Pengambilan sampel ikan pada lokasi pengamatan menggunakan alat tangkap pukat hela. Hasil pengamatan morfometrik berdasarkan 11 indikator karakteristik morfometrik dan 5 indikator karakteristik meristik ikan nomei yang berasal dari perairan Sebatik dan Tarakan kecenderungan memiliki hasil yang sama. Dari pengamatan morfometrik dan meristik ikan nomei diketahui bahwa ikan nomei di perairan Kalimantan Utara termasuk kedalam spesies Harpadon nehereus.
\end{abstract}

KATA KUNCI: Ikan nomei; karakteristik morfometrik; karakteristik meristik

\section{ABSTRACT}

This research aims to describe the morphometric and characteristics of nomei fish (Harpadon nehereus) in the waters of North Kalimantan was implemented in August to October 2018. The data collection method used was random sampling. The determination of the station is based on the location of fishing for Nomei in Sebatik and Tarakan waters. Sampling of fish at the fishing location using a trawler. Morphometric observations based on 11 morphometric and 5 meristic characteristics indicators of nomei fish originating from Sebatik and Tarakan waters tend to have the same results. It is known from morphometric and meristic observation of nomei fish that nomei fish in the waters of North Kalimantan belongs to the Harpadon nehereus species.

KEYWORDS: Nomei fish; morfometric; meristic characteristic

\section{PENDAHULUAN}

Ikan demersal adalah jenis-jenis ikan yang sebagian besar kehidupannya berada di dasar atau dekat dasar perairan (Yulianto et al., 2016). Saat ini Tarakan terkenal dengan produksi ikannya, memiliki potensi

\# Korespondensi: Sekolah Tinggi Perikanan

E-mail: ratnastp.rs75@gmail.com perikanan tangkap (Bonte dan Firdaus, 2012) sebesar 8.560 ton pertahun, dengan telah dimanfaatkan 7.900 ton pertahun atau $92,29 \%$ pertahun (Susilawati et al., 2015). Jumlah Produksi (ton/tahun) di Nunukan pada tahun 2008 sebesar 4.535,70 ton pertahun (Solihin et al., 2011). Tingginya eksploitasi ikan demersal di Kalimantan Utara khususnya Tarakan dan sekitarnya dengan alat tangkap trawl dan sejenisnya 
mengindikasikan terjadinya pemanfaatan berlebih terhadap stok ikan demersal di daerah penangkapan tersebut (Purwanto, 2015; Suman, 2011).

Ikan Nomei hidup di dasar, lumpur, daerah pantai, muara sungai, memiliki panjang $40 \mathrm{~cm}$, dan umumnya $10-25 \mathrm{~cm}$. Ikan Nomei tergolong buas, makanannya berupa binatang dasar, ikan - ikan kecil. Ikan nomei merupakan ikan laut lokal yang ditemukan di wilayah perairan Tarakan (Nugroho dan Salurapa, 2017) dan merupakan salah satu ikan demersal yang memiliki nilai ekonomis tinggi di Tarakan (Nugroho dan Rahayu, 2014). Namun hasil penangkapan ikan nomei mengalami penurunan dalam beberapa tahun terakhir (Nugroho dan Rahayu, 2014). Penangkapan yang dilakukan secara terus-menerus akan berdampak pada pendapatan nelayan yang mulai turun dan punahnya ikan ini di habitat ekosistem. Aktivitas ini ditelusuri karena kurangnya kepedulian terhadap kelestarian habitat ekosistem ikan di perairan Tarakan (Nugroho dan Salurapa, 2017).

Pengelolaan lestari tentu seharusnya memiliki dasar sains yang kokoh (Ndobe et al., 2013). Data penelitian ikan nomei saat ini masih kurang, selama ini penelitian yang telah dilakukan terbatas pada aspek penangkapan, bioekologi, dan biologinya. Pengelolaan yang didasarkan pada informasi biologis sangat diperlukan dalam upaya mempertahankan kelestarian ikan nomei (Harpadon nehereus). Kajian taksonomi ikan nomei terbatas pada kajian literature, Jabarsyah (2005) dan DKP Kota Tarakan(2002) menyebutkan bahwa ikan nomei yang ada di Tarakan termasuk spesies Horpodon nehereus Ham Buch, sehingga diperlukan pengkajian lebih lanjut. Tujuan penelitian ini adalah identifikasi ikan nomei yang ada di tarakan melalui pengamatan karakter morfologi yang meliputi studi karakteristik morfometrik dan meristik.

\section{METODE PENELITIAN}

Penelitian dilaksanakan pada bulan Agustus sampai dengan Oktober 2018 di Tarakan, Desa Mantikas dan Desa Binalawan, Kecamatan Sebatik, Nunukan, Provinsi Kalimantan Utara (Gambar 1). Metode pengambilan data yang digunakan adalah metode random sampling. Penentuan stasiun dilakukan berdasarkan lokasi penangkapan ikan nomei (Harpadon nehereus). Pengambilam sampel ikan nomei dilakukan setiap dua minggu sekali menggunakan alat penangkap ikan nomei yaitu kapal pukat hela, ikan yang tertangkap dalam jarring diamati $10 \%$ dari total ikan yang didapatkan, meliputi ikan jantan dan betina. Pengamatan karakter morfologi meliputi karakter umum ikan nomei yang ditemukan (234 ekor (85 jantan dan 149 betina), karakterisasi morfometrik, meristrik dan karakter khusus. Alat yang digunakan untuk mengukur morfometrik ikan adalah meteran dengan ketelitian $1 \mathrm{~mm}$, jangka sorong dengan ketelitian $0.05 \mathrm{~mm}$ size $6 "$ ", alat bedah dan timbangan dengan ketelitian $1 \mathrm{gr}$.

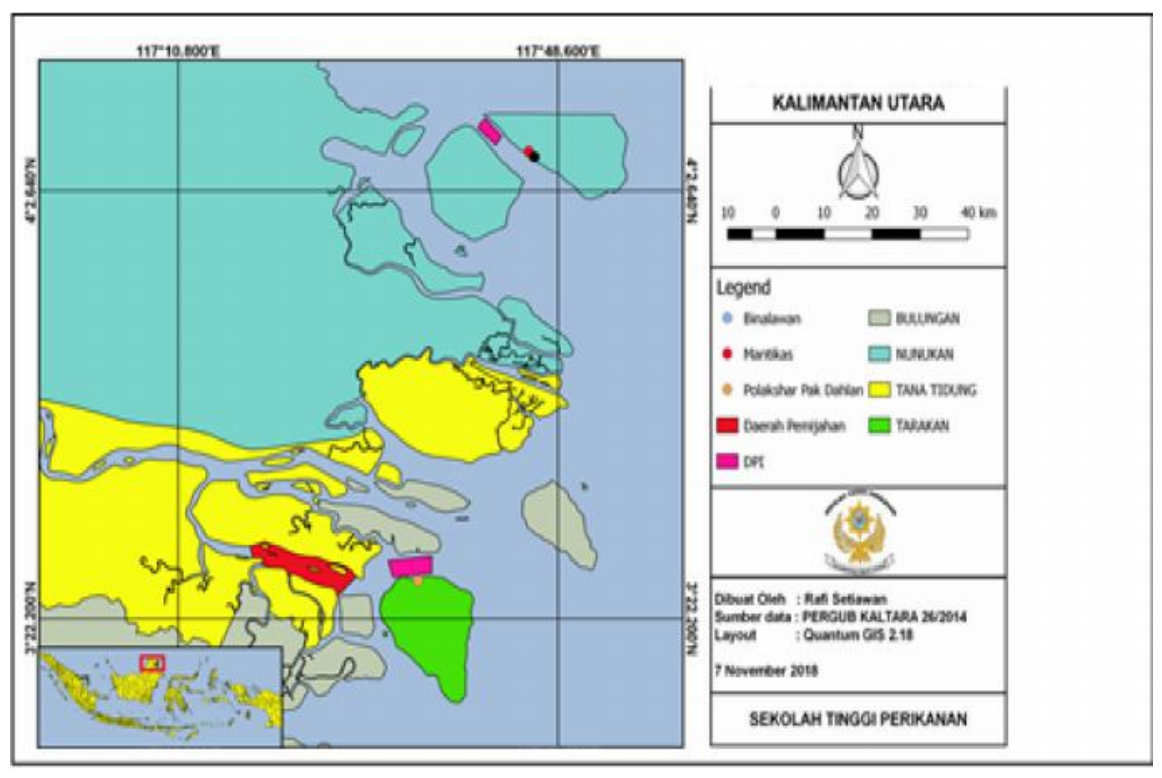

Gambar 1. Lokasi Pengamatan di Desa Mantikas dan Desa Binalawan.

Figure 1. Observation Location Mantikas Village and Binalawan Village. 
Pengamatan karakter morfometrik yang digunakan sebanyak 11 karakter dapat dilihat pada Gambar 2. Standarisasi ukuran tubuh dilakukan homogenisasi dengan membagi setiap karakter morfometrik dengan panjang standar (SL) dan diubah menjadi 100 persen. Setelah didapat hasil pengukuran morfometrik, kemudian menghitung persentase dari morfometrik ikan tersebut (Nugroho et al., 2010) dengan:

$$
\text { Persentase }=\frac{\mathrm{N}}{\text { Panjang Standar }} \times 100 \%
$$

Data yang telah dibuat dalam bentuk persen diubah menjadi $\log 10$, dan karakter meristik yang diukur jumlah jari-jari sirip dorsal, jumlah jari-jari sirip anal, jumlah jari-jari sirip ventral, jumlah jari-jari sirip pektoral, jumlah jari-jari sirip ekor (Nugroho et al., 2010), dapat dilihat Gambar 2 dan 3. Hasil dari pengamatan morfometrik ikan putih akan dibandingkan dengan genus lainnya melalui Fishbase, California Academy of Sciences dan Wikispecies.

Analisis karakter meristik dilakukan menggunakan Statistica 10.0, analisis PCA (proncipal componen analysis) untuk diketahui variabel-variabel yang mendiskriminasi sampel yang diuji dan mencocokan data yang diambil pada FishBase secara online dan dicocokkan dengan buku kunci identifikasi ikan.

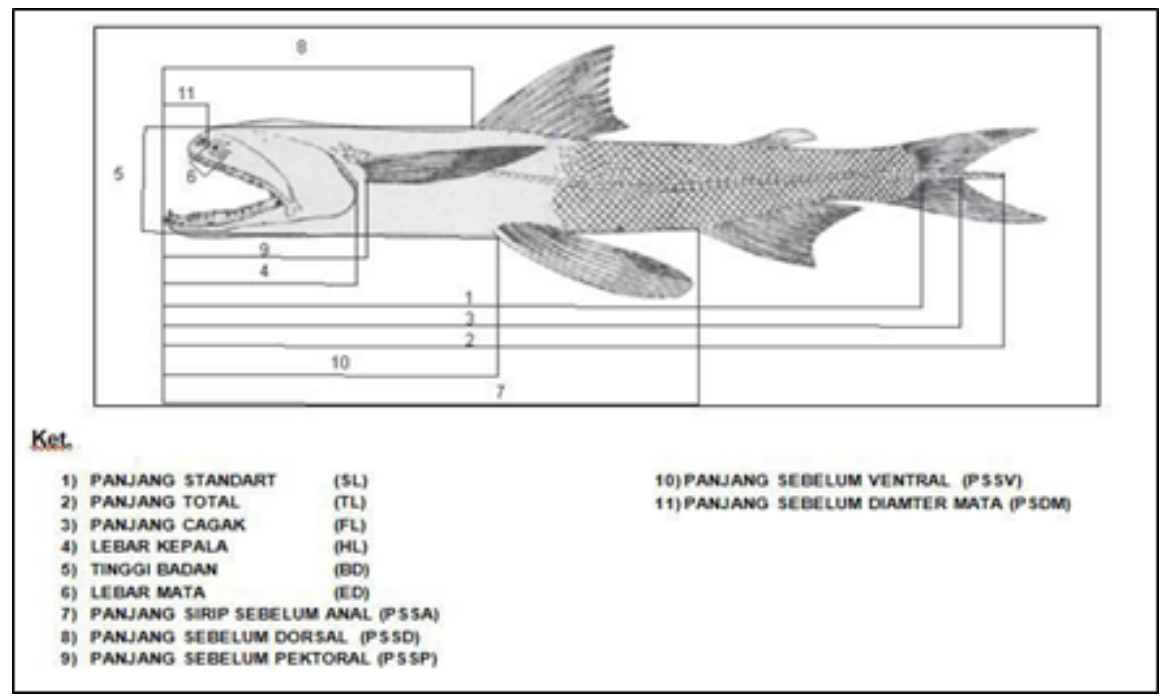

Gambar 2. Morfometrik ikan nomei (Frosse and Pauly,2018).

Figure 2. Morphometric nomei fish (Frosse and Pauly,2018).

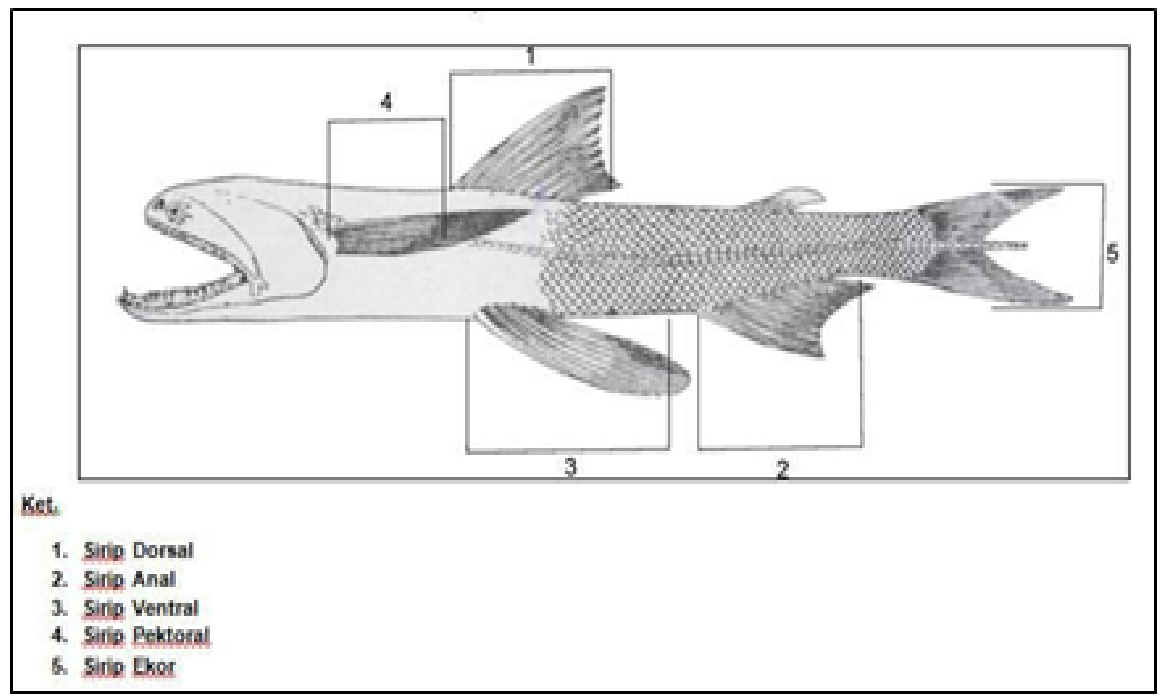

Gambar 3. Meristik ikan nomei (Nugroho and Salurapa.,2017).

Figure 3. Morphometric nomei fish (Nugroho and Salurapa 2017). 


\section{HASIL DAN PEMBAHASAN}

Hasil pengamatan karakteristik ikan nomei di Tarakan dan Sebatik memiliki tubuh panjang seperti torpedo, mata berukuran kecil, jarak mata dengan ujung hidung sempit, mulut lebar dan panjang, sisik pada garis rusuk memanjang melampaui lekukan lembaran sirip ekor, permulaan sirip ventral di belakang punggung, tipe mulut superior, memiliki sirip lemak pada bagian dorsal sirip ekor memanjang membentuk tiga bagian, ujung moncong pendek, terdapat sungut didalam mulut yang bewarna merah, memiliki sirip pektoral panjang (mencapai atau melebihi sirip dorsal), bentuk sirip dorsal cekung, bentuk sirip anal cekung, bentuk sirip pelvic membulat, sebagian besar kepala ditutupi oleh sisik yang agak tipis, dan memiliki warna tubuh putih keabu-abuan kemerahan. Hasil identifikasi karakter morfologi dengan menggunakan bantuan website fishbase.org dan Ganga and Sukumaran, (2015) diketahui bahwa ikan nomei yang ada di Tarakan dan Sebatik merupakan spesies Harpadon nehereus. Nelayan di Kalimantan Utara memiliki banyak sebutan yaitu, ikan nomei, ikan pepija, ikan tipis dan ikan lacocina. Morfologi ikan nomei (H. nehereus) disajikan pada Gambar 4.

Dari hasil pengamatan morfometrik ikan nomei (H. nehereus), berdasarkan 11 karakter (Tabel 1) terlihat bahwa karakteristik morfometrik ikan nomei yang berasal dari Tarakan dan Sebatik kecenderungan memiliki hasilnya sama.

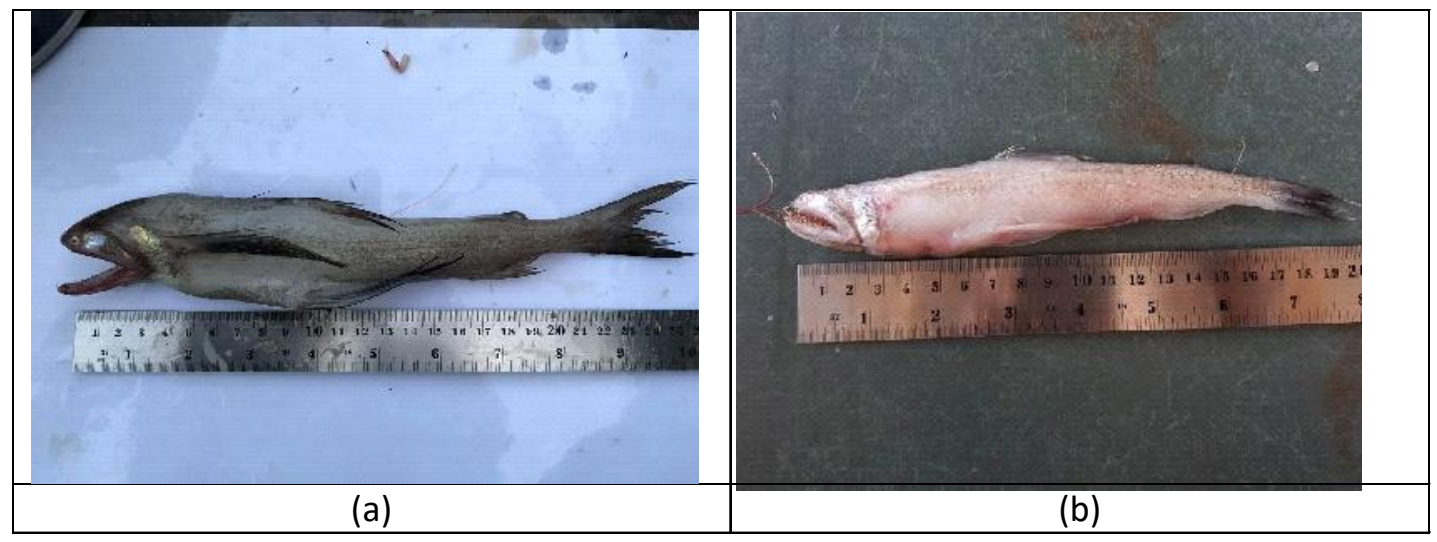

Gambar 4. Morfologi ikan nomei (Harpadon nehereus) di kecamatan Juata Laut, Tarakan (a) dan Desa Mantikas, Sebatik (b).

Figure 4. Morphology of nomei fish (Harpadon nehereus) in Juata Laut sub-districts, Tarakan (a) and Mantikas Village, Sebatik (b).

Tabel 1. Kisaran morfometrik ikan nomei (H. nehereus)

Table 1. Morphometric range of nomei fish (H. nehereus)

\begin{tabular}{ccccccc}
\hline \multirow{2}{*}{ Karakteristik } & \multicolumn{3}{c}{ Tarakan } & \multicolumn{3}{c}{ Sebatik } \\
\cline { 2 - 6 } & Kisaran & Rata-Rata & SD & Kisaran & Rata-rata & SD \\
\hline SL & $15.5-25.5$ & 18.90 & 1.66 & $15.5-23$ & 18.89 & 1.70 \\
TL & $18.6-29$ & 21.79 & 1.89 & $19-27$ & 21.92 & 2.08 \\
FL & $17-27$ & 20.03 & 1.88 & $17.3-25.5$ & 20.47 & 2.09 \\
HL & $3-6.4$ & 4.10 & 0.90 & $3-5.5$ & 3.92 & 0.59 \\
BD & $2-5.5$ & 3.32 & 0.66 & $2.2-5.5$ & 3.42 & 0.75 \\
ED & $0.14-0.57$ & 0.33 & 0.09 & $0.17-0.57$ & 0.33 & 0.09 \\
PSSA & $10-20.4$ & 14.98 & 1.61 & $10-19.6$ & 14.77 & 1.93 \\
PSSD & $4.11-11$ & 7.61 & 1.06 & $5-10.5$ & 7.72 & 1.23 \\
PSSP & $2.00-8$ & 4.68 & 0.69 & $3.2-6$ & 4.48 & 0.59 \\
PSSV & $6.4-14.2$ & 8.67 & 1.02 & $6.8-11.2$ & 8.50 & 1.04 \\
PSDM & $0.25-0.51$ & 0.28 & 0.06 & $0.2-0.51$ & 0.29 & 0.07 \\
\hline
\end{tabular}


Komponen yang dianalisis lebih lanjut adalah komponen matriks kovarian yang dikategorikan sebagai shape factor yang digunakan untuk analisis divergensi morfologi (Gambar 5). Hasil Analisis PCA Multivariant ikan nomei menunjukan bahwa ikan betina dan jantan dari kedua lokasi tersebut memiliki karakter yang berdekatan hal ini menunjukan bahwa ikan nomei di perairan Kalimantan Utara memiliki perbedaan lingkungan tetapi faktor makanan di lingkungan habitatnya sama. Diindikasikan dari pertumbuhan yang dicapai oleh ikan nomei baik jantan maupun betina. Firdaus (2010), ketersediaan makanan pada perairan yang dipilih sebagai salah satu daerah tempat mencari makanan, sehingga ketersediaan makanan yang cukup akan membuat ikan dapat tumbuh dengan baik. Nugroho dan Rahayu (2011) menyatakan bahwa setiap spesies mempunyai sebaran geografi tertentu yang dikontrol oleh kondisi fisik lingkungannya. Oleh karena itu, sebaran dan variasi morfometrik yang muncul merupakan respon terhadap lingkungan fisik tempat hidup spesies tersebut.

Hasil pengamatan karakter meristrik pada ikan nomei didapatkan hasil sebagai berikut memiliki jumlah sirip dorsal sebanyak D12-13 jari-jari sirip yang bercabang, sirip pektoral memiliki 10-12 jari-jari lemah dan bercabang, sirip ventral dengan 10-12 jari-jari lemah dan bercabang, dan sirip anal dengan 13-15 jarijari lemah dan bercabang. Berdasarkan hasil pengamatan dan dibandingkan dengan Catalog of fishes and fishbase maka spesies ikan nomei yang ada pada perairan Kalimantan Utara termasuk kedalam spesies Harpadon nehereus (Catalog of fishes and fishbase). Berdasarkan hasil perhitungan meristik jarijari sirip terdapat perbedaan jumlahnya dibandingkan dengan pustaka lain, hal ini menjelaskan adanya variasi spesies, ataupun faktor yang mempengaruhinya (Afini et al.,2016). Karakter meristik ikan nomei di perairan Kalimantan Utara disajikan pada Tabel 2.

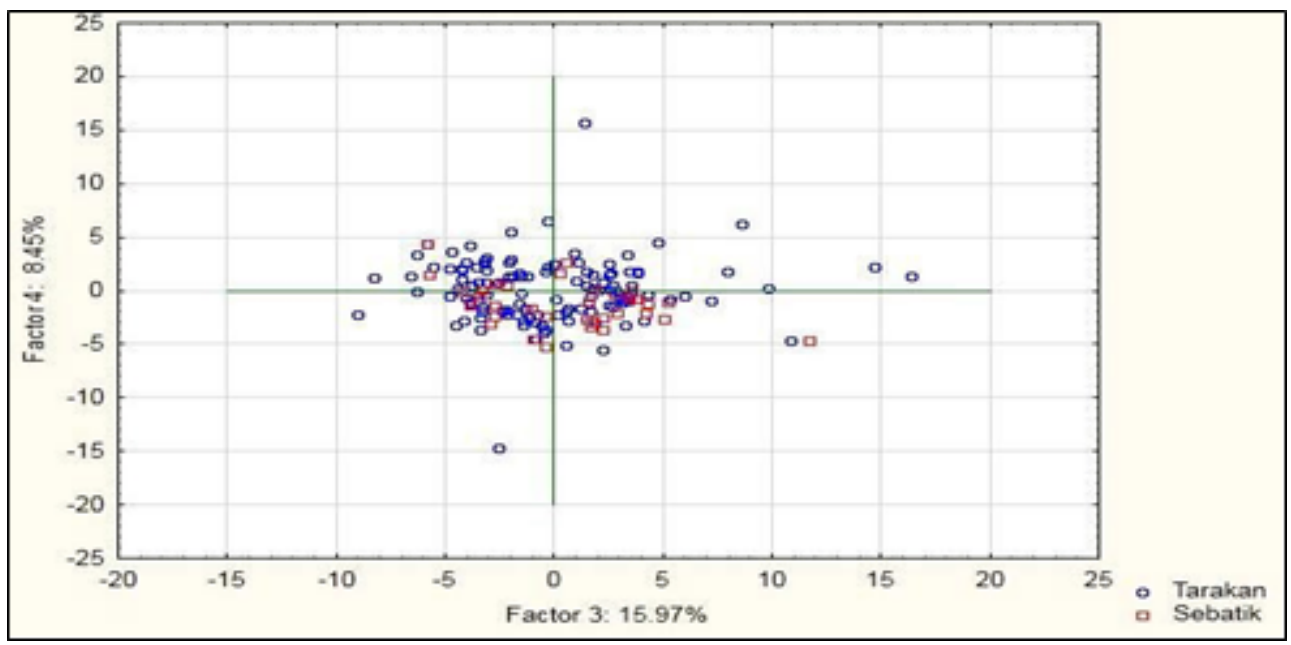

Gambar 5. Analisis PCA Multivariant ikan nomei.

Figure 5. Multivariant PCA analysis of nomei fish.

Tabel 2. Kisaran meristik ikan nomei di Kalimantan Utara

Table 2. Range of nomei fish meristic in North Kalimantan

\begin{tabular}{|c|c|c|c|c|c|c|c|}
\hline \multirow{2}{*}{ No } & \multirow{2}{*}{ Karakter } & \multicolumn{6}{|c|}{ Kisaran Meristik } \\
\hline & & Tarakan & Sebatik & $\begin{array}{l}\text { H. } \\
\text { nehereus }\end{array}$ & $\begin{array}{l}\text { H. } \\
\text { m icroch ir }\end{array}$ & $\begin{array}{l}\text { H. } \\
\text { translucens }\end{array}$ & $\begin{array}{l}\text { H. } \\
\text { squamosus }\end{array}$ \\
\hline 1 & $\begin{array}{l}\text { Jum lah } \\
\text { Sirip }\end{array}$ & $12-14$ & $12-14$ & $12-13$ & 14 & 14 & $12-14$ \\
\hline 2 & $\begin{array}{l}\text { Jum lah Sirip } \\
\text { Anal }\end{array}$ & $13-15$ & $13-15$ & $14-15$ & $14-15$ & 14 & $13-15$ \\
\hline 3 & $\begin{array}{l}\text { Jum lah } \\
\text { Sirip }\end{array}$ & 9 & 9 & 9 & 12 & 12 & 10 \\
\hline 4 & $\begin{array}{l}\text { Jum lah } \\
\text { S irip }\end{array}$ & $10-12$ & $10-12$ & $11-12$ & 9 & - & 9 \\
\hline 5 & $\begin{array}{l}\text { Jum lah } \\
\text { Sirip }\end{array}$ & $22-30$ & $22-30$ & - & - & - & - \\
\hline
\end{tabular}


Daerah penangkapan ikan ikan nomei di Kalimantan Utara merupakan daerah aliran sungai yang dangkal, pertemuan arus dikeliling area hutan bakau, sehingga relatif lebih tenang. Berdasarkan hasil wawancara dengan nelayan setempat menyatakan bahwa ikan nomei ini akan ada saat air mati, diikuti dengan adanya lumba-lumba albino yang merupakan kepercayaan masyarakat setempat sebagai simbol keberentungan. Penangkapan ikan nomei dilakukan oleh nelayan pada umumnya menggunakan pukat hela pada musim tertentu saja yaitu pada saat kondisi air laut mengalami surut, kondisi ini merupakan kondisi dimana ikan sangat berlimpah. Dalam satu bulan air laut mengalami surut 2 kali. Waktu penangkapan ikan Nomei dalam satu musim penangkapan hanya 4-5 hari, dalam satu bulan hanya 8-10 hari saja. Intensitas penangkapan yang terus meningkat dan berlangsung terus menerus tanpa ada masa jeda maka dikhawatirkan populasi ikan Nomei akan semakin menurun. Dari hasil pengamatan sebagian besar nelayan menggunakan ukuran mata jarring yang cukup kecil yaitu 0.5 inchi sehingga ikan yang belum matang gonad tertangkap sehingga akan menimbulkan dampak pada hasil tangkapan berikutnya karena ikan yang tertangkap belum sempat memijah dikhawatirkan akan terjadi degradasi kelangsungan hidup ikan nomei di alam yang dapat mengakibatkan terjadinya penurunan hasil tangkapan dan kepunahan di perairan.

Pemerintah setempat membuat Peraturan Gubernur Kalimatan Utara No. 26 Tahun 2014 Tentang Pengelolaan Ikan Nomei di Wilayah Perairan Provinsi Kalimantan utara yang bertujuan untuk melindungi kelangsungan populasi ikan nomei. Semua kebijakan yang berkaitan dengan pengelolaan harus ditujukan terutama untuk mendorong perkembangan perikanan yang ada di Provinsi Kalimantara Utara. Teknik pengelolaan perikanan dapat dilakukan dengan beberapa cara, diantaranya adalah dengan pengaturan ukuran mata jaring pada alat tangkap yang digunakan; pengaturan batas ukuran ikan yang boleh ditangkap, didaratkan, atau dipasarkan; kontrol terhadap musim dan daerah penangkapan; pengaturan terhadap alat tangkap; serta perbaikan dan peningkatan sumberdaya hayati. Tanpa pengelolaan bersama, implementasi pengelolaan dipastikan tidak akan berjalan dengan baik dan tidakan akan mencapai tujuan (Suman et al., 2016).

\section{KESIMPULAN}

Ikan nomei di di Kalimantan Utara mempunyai karakteristik morfometrik dan meristik termasuk kedalam spesies Harpadon nehereus (Catalog of fishes and fishbase). Untuk melindungi kelangsungan populasi ikan nomei pemerintah setempat membuat Peraturan Gubernur Kalimatan Utara No. 26 Tahun 2014
Tentang Pengelolaan Ikan Nomei di Wilayah Perairan Provinsi Kalimantan utara.

\section{UCAPAN TERIMA KASIH}

Terima kasih diucapkan kepada DKP Provinsi Kalimantan Utara, DKP Kota Tarakan, DKP Kabupaten Nunukan, SPKT Sebatik atas bantuan yang diberikan selama dalam penelitian. Ucapan terima kasih juga kami sampaikan kepada civitas akademika Sekolah Tinggi Perikanan, masyarakat Desa Juwata Laut, Desa Mantikas, Desa Binalawan serta pihak lainnya yang tidak bisa disebutkan satu persatu.

\section{DAFTAR PUSTAKA}

Afini, I., Elfidasari, D., Kadarini, T., \& Musthofa, S. Z. (2015). Analisis Morfometrik dan Meristik Hasil Persilangan Ikan Pelangi Boesemani (Melanotaenia boesemani) dan Ikan Pelangi Merah Abnormal (Glossolepis incisus). Life Science, 5(1), 8057.

Bonte, S. B., \& Firdaus, M. (2012). Perbedaan Soaking Time Terhadap Hasil Tangkapan Pada Perikanan Tugu (Trap Net) di Perairan Timur Kota Tarakan, Jurnal Harpodon Borneo, 5(2), 147-159.

Firdaus, M. (2010). Hasil Tangkapan dan Laju Tangkap Unit Perikanan Pukat Tarik, Tugu, dan Kelong,Makara, Teknologi, 14(1), 22-28.

Froese, R. \& D. Pauly (2018). FishBase. World Wide Web electronic publication. Diakses 15 Agustus 2018.

Ganga, U., P., J., \& Sukumaran, S. (2015). A New Species of the Genus Harpadon (Aulopiformes , Synodontidae) from the A New Species of the Genus India. Indian J. Fish., 62(4) : 1-9, 2015

Ndobe, S., Widiastuti, I., \& Moore, A. (2013). Sex Ratio dan Pemangsaan terhadap Rekrut pada Ikan Hias Banggai Cardinalfish (Pterapogon kauderni), 9-20. Konferensi Akuakultur Indonesia.

Nugroho, E. D., \& Rahayu, D. A. (2014). Variasi Morfologi dan Kekerabatan Ikan Nomei Perairan Kalimantan Sebagai Upaya Konservasi Ikan Laut Lokal di Indonesia. Proceeding Biology Education Conference 505-511. Semarang, Seminar Nasional XI Pendidikan Biologi FKIP UNS .

Nugroho, E. D., Rahayu, D. A., Amin, M., \& Lestari, U. (2010). Status Taksonomi Ikan Laut Lokal Tarakan, Kalimantan Utara Sebagai Langkah Awal Upaya Konservasi. Prosiding Seminar Nasional Ikan ke 8 87-96. Iktiologi Indonesia.

Nugroho, E. D., \& Salurapa, A. (2017). Preferensi Pemijahan dan Habitat Ikan Nomei (Harpodon nehereus) Di Perairan Juata Laut Tarakan Sebagai Upaya Konservasi, Jurnal IImiah Biologi, 5(1), 5560. 
Purwanto. 2015. Biomasa, Produktivitas Kapal Penangkap dan Potensi Produksi Ikan Demersal di Laut Arafura, 187- 199.

Solihin, I., Wisudo, S. H., Haluan, J., \& Martianto, D. (2011). Pengembangan Produksi Perikanan Tangkap Di Wilayah Perbatasan (Kasus Kabupaten Nunukan Kalimantan Timur)/ , Buletin PSP, 19 (2), 9-18.

Suman, A. (2011). Stok Sumberdaya Ikan Demersal Laut Dalam di Perairan ZEEI Samudera Hindia Sebelah Selatan Jawa. Balai Riset Perikanan Laut. Majalah Ilmiah Biologi: A Scientific Journal 28 (1), 1-8.

Suman, A., Irianto, H. E., Satria, F., \& Amri, K. (2016). Potensi Dan Tingkat Pemanfaatan Sumber Daya
Ikan di Wilayah Pengelolaan Perikanan Negara Republik Indonesia (WPP NRI) Tahun 2015 Serta Opsi Pengelolaannya. Jurnal Kebijakan Perikanan Indonesia, $8(21)$, 97-110.

Susilawati, Mulyadi, A., \& Mubarak (2015). Analisis Sebaran Schooling Ikan Demersal di Perairan Tarakan Kalimantan Utara Menggunakan Metode Hidroakustik. Jurnal Online Mahasiswa Fakultas Perikanan dan Ilmu Kelautan Universitas Riau (JOM FAPERIKA UNRI), 2(15), 1-16.

Yulianto, G., Suwardi, K., Adrianto, L., \& Machfud (2016). Status Pengelolaan Sumberdaya Ikan Demersal Sekitar Pantai di Kabupaten Indramayu, Jawa Barat. Omni Akuatika, 12(3), 1-10. 
